\title{
PHOTODIODE BASED ON THE EPITAXIAL PHOSPHIDE GALLIUM WITH INCREASED SENSITIVITY AT A WAVELENGTH OF 254 nm
}

\author{
Yurii G. Dobrovolsky ${ }^{1}$, Volodymyr M. Lipka ${ }^{2}$, Volodymyr V. Strebezhev ${ }^{1}$, Yurii O. Sorokatyi ${ }^{1}$, \\ Mykola O. Sorokatyi ${ }^{\text {, Olga P. Andreeva }}{ }^{2}$ \\ ${ }^{1}$ Yuriy Fedkovych Chernivtsi National University, Chernivtsy, Ukraine, ${ }^{2} \mathrm{PJC}$ "CDB” Rhythm", Chernivtsy, Ukraine
}

Abstract. The paper shows the results of the development of a photodiode technology based on gallium phosphide structure $n^{+}-n-G a P$-Au with high sensitivity. It provides the ion etching of the surface of the gallium phosphide before an application of a leading electrode of gold. The barrier layer of a $20 \mathrm{~nm}$ thick gold is applied to the substrate in the magnetic field of GaP. When forming the contact with the reverse side of the indium substrate at $600^{\circ} \mathrm{C}$, there occurs the annealing of the gold barrier layer. At the maximum of the spectral characteristics obtained by the photodiode, it has a sensitivity of $0.13 \mathrm{~A} / \mathrm{W}$, and at a wavelength of $254 \mathrm{~nm}$ - about $0.06 \mathrm{~A} / \mathrm{W}$. The dynamic range of the photodiode is not less than $10^{7}$.

Keywords. photodiode, gallium phosphide, sensitive, $254 \mathrm{~nm}$, Schottky barrier

\section{FOTODIODA OPARTA NA EPITAKSJALNYM FOSFORKU GALU O ZWIĘKSZONEJ WRAŻLIWOŚCI PRZY DLUGOŚCI FALI 254 nm}

Streszczenie. Artykut pokazuje rezultaty rozwoju technologicznego fotodiody opartej na fosforku galu o strukturze $n^{+}$-n-GaP-Au o wysokiej czułości. Umożliwia to wytrawianie jonowe powierzchni fosforku galu, zanim zastosowana zostanie elektroda przewodzaca wykonana ze złota. Złota warstwa barierowa o grubości $20 \mathrm{~nm}$ jest nakładana na podtoże GaP w polu magnetycznym. Gdy powstaje styk z tylu podłoża indowego w temperaturze $600^{\circ} \mathrm{C}$, złota warstwa barierowa jest wyżarzana. Przy maksymalnej charakterystyce spektralnej uzyskanej przez fotodiodę, ma ona czułość 0,13 A/W, a przy dtugości fali $254 \mathrm{~nm}$ - około 0,06 A / W. Zakres dynamiczny fotodiody wynosi co najmniej $10^{7}$.

Slowa kluczowe: fotodioda, fosforek galu, czułośc, $254 \mathrm{~nm}$, bariera Schottky'ego

\section{Introduction}

Gallium phosphide $(\mathrm{GaP})$ is an effective material for photodiodes with Schottky barrier, sensitive in the ultraviolet region of the spectrum, which is now being actively developed in the branch of optoelectronics. This material is substantially transparent to optical radiation, because it has a wavelength of about 0.5 microns. As such, the photodiodes made of a gallium phosphide do not require complex filters to "cut" the visible and infrared radiation. In comparison to the more effective material in terms of sensitivity - gallium nitride $(\mathrm{GaN})$, gallium phosphide has a substantially lower cost, which allows it to remain relevant in the market of the photodiodes that are sensitive in the ultraviolet region of the spectrum.

Such photodiodes are used, in particular, for the creation of the UV radiation radiometer because they have, in this case, the photovoltaic mode. As such, the most effective photodiodes are based on epitaxial $n^{+}-n^{-}$structures with a carrier concentration in the epitaxial layer of about $10^{16} \mathrm{~cm}^{-3}$ [7]. As the active electrode, there is used a metal film (mostly - semi-transparent layer of gold) $[1,7]$, or a thin conductive ITO layer (a mixture of $\mathrm{SnO}_{2}$ and $\left.\mathrm{In}_{2} \mathrm{O}_{3}\right)$, and also FTO $\left(\mathrm{SnO}_{2}\right.$ layer, fluorine-doped) [8], which may be made by pulverization [2]. It provides high sensitivity $(0.2 \mathrm{~A} / \mathrm{W}$ at $450 \mathrm{~nm}$ - a peak of spectral sensitivity characteristic). The disadvantages of this technology are that it provide high sensitivity unevenness on the surface of the photosensitive member (over 10\%) even in the case of a film deposition by magnetron sputtering of metal oxides. The cause of this phenomenon lies in the fact that the film begins to grow islets. And it is not possible to obtain uniformly thick layer at a film thickness smaller than $30 \mathrm{~nm}$ [4]. For the same reason, up to $30 \%$ of films made by the photodiodes in each cycle are defective. The sensitivity at a wavelength of $\sim 250 \mathrm{~nm}$ is not pains $0.05 \mathrm{~A} / \mathrm{W}$.

To increase the value of the current monochromatic sensitivity, authors of [6], found that the structure formation based on $\mathrm{AlGaN}$ with a gold transparent contact, as in the case of gallium phosphide, exhibits the highest sensitivity among photodiodes, in a Schottky barrier, and the structure of the heat treatment showed that the contact annealing increases the photosensitivity three times. This effect is illustrated by authors [6] and they show the fact that a layer of oxide is on the AlGaN surface after chemical cleaning. In total, after the deposition of the gold contact, there is obtained a metal structure - a dielectric (thin oxide film) - semiconductor. The process of annealing of the formed structure, according to the authors of [6], partially diffuses through the oxide layer closer to the semiconductor surface, which reduces the resistance of the whole structure and, as a consequence.

Obviously, such a situation occurs and the photodiode is based on the second compound semiconductor including gallium phosphide.

A view of this work is based on the optimization technique of photodiodes $\mathrm{n}^{+}-\mathrm{n}-\mathrm{GaP}-\mathrm{Au}$ to increase the current monochromatic sensitivity at a wavelength of $254 \mathrm{~nm}$.

\section{Results of research}

Preliminary assessment of the design and technology of the new photodiode was carried out in accordance with [5]. This software is designed to find ways to increase the sensitivity of photodiodes operating in the photodiode regime. An analysis and calculation results compared with the results of the current measurement of sensitivity to monochromatic $450 \mathrm{~nm}$ showed that, despite the effectiveness of the propsed optimization method, it does not fully fit the situation, when the photodiode operates in the photovoltaic mode.

The known algorithm is also not provided for the calculation of the optical properties of the photodiode surface by the amount of its sensitivity. The surface consists of at least three media: air AR coating - the semiconductor surface.

In our case, in the operating wavelength range $(200-500 \mathrm{~nm})$, there is almost a complete absorption of the optical radiation (up to $86 \%$ is caught in a semiconductor layer of radiation) that takes place in a layer that is 1.5 microns thick [5]. This is why the most effective is a photodiode structure based on the epitaxial structure of $\mathrm{n}^{+}-\mathrm{n}^{-}$type in which a working layer - the layer in which optical radiation is absorbed is n-type high-resistance layer - was disposed on the low-resistance substrate.

To determine the maximum possible value of the sensitivity that can be obtained in this case, the inventors have used the approach described in [4], which suggested to maximize the sensitivity of the photodiode structure, ensuring the system of inequalities (1), which contain the basic parameters of the photodiode structure and the physical parameters of the material. 


$$
\left\{\begin{array}{l}
x_{0}<h_{\ni c} \leq\left(L_{p}+x_{0}+h\right) \\
L_{p}<\left(h_{\ni c}-x_{0}\right) \\
\alpha_{\kappa}<x_{0} \leq L_{p} \\
d=\lambda(2 n+1) / 4 \\
I_{F} S \cong S_{\text {int }} p
\end{array}\right.
$$

where: $x_{0}$ - the width of the space charge region in the epitaxial layer, $h_{e s}-$ thickness of the epitaxial layer, $L_{p}-$ the diffusion length of holes, $h$ - the depth of field propagation due to the impurity concentration distribution profile, $\alpha_{k}-$ absorption depth shortwave (UV) radiation in gallium phosphide, $d$ - thickness of the metal oxide layer, $\lambda$ - wave length, $n$ - the refractive index of the metal oxide film, $R$ - the value of the optical flux, $S_{\text {Int }}-$ the integral sensitivity due to optical radiation incident on the photodiode, $I_{F}$ - the specific value of the photocurrent generated in that unit area which provides sensitivity $\mathrm{S}_{\text {int }}, S$ - the area of the photosensitive element illuminated by the incident optical radiation to the photodiode.

The first expression defines a region collecting photogenerated carriers that generate a long-wavelength component of the spectral sensitivity range of the photodiode, the second component - a high-resistivity isolation protects the epitaxial layer from the influence of the charge carriers generated in the low-resistance substrate, and the epitaxial structure, the third component, provides a short-range contribution. The fourth reflection phenomenon takes into account the flow of optical radiation from the surface of an optical transparent conductive metal oxide electrode and the surface of the metal oxide film section semiconductor (gallium phosphide). The fifth considers a photosensitive member area, which may depend on the magnitude of the photocurrent when the photodiode is illuminated by the entire marketplace stream R.

An analysis of equations and inequalities (7) conducted in the MS Office Excel 2003 showed that the maximum sensitivity in the wavelength range $250-450 \mathrm{~nm}$ can reach $0.1-0.17 \mathrm{~A} / \mathrm{W}$.

\section{Technology of the photodiode}

To create the structure of a photodetector there was used an epitaxial $\mathrm{n}^{+}$-n-type conductivity with a total thickness of 300-370 microns. Orientation GaP substrate [11], the concentration of charge carriers in the substrate was $(1-4) \times 10^{17} \mathrm{~cm}^{-3}$. The thickness of the epitaxial n-type layer does not exceed 15 microns, and the concentration of charge carriers does not exceed $(0.9-2) \times 10^{16} \mathrm{~cm}^{-3}$.

Proposed was the technology of obtaining a structure of $\mathrm{n}^{+}-\mathrm{n}-\mathrm{GaP}-\mathrm{Au}$, which provides ionic surface etching of gallium phosphide before the application of a leading electrode of gold. Such operation helps to maximize the purification of the wafer surface, which in turn prevents the formation of chaotic, uncontrolled $\mathrm{Au}$ film growth centres during its application Further, AuGaP layer is applied to the plate in a magnetic field. Experiments have shown that it promotes a more uniform distribution of the Au layer on the surface of the wafer of gallium phosphide and provides a more reliable adhesion. Before applying the gold film, the gallium phosphide surface was treated with a solution of bromine in dimethylformamide followed by rinsing in alcohol.

Then, after the ion etching the surface of the wafer, by thermal evaporation under vacuum, deposited is a barrier layer of gold. A layer of gold is deposited at a temperature of $370 \pm 10^{\circ} \mathrm{C}$. In this case, the substrate temperature was controlled not to fall below $100^{\circ} \mathrm{C}$. The thickness of the barrier layer was $20 \mathrm{~nm}$.

Ohmic contact with the gold layer of the barrier was also created by thermal evaporation under vacuum at a temperature of
$370 \pm 10^{\circ} \mathrm{C}$ and a substrate temperature of at least $100^{\circ} \mathrm{C}$. The thickness of the contact layer was 0.7 microns.

The magnetic field in the area of application of the barrier layer of gold was formed using gyrotropic cylindrical capacitor which consists of a ring-based material with an external ferrodielectric $R_{1}$ and inner radius $R_{2}$, and a thickness $D$. The magnetic field of the ring is oriented in such a way that the south and north poles are located on the opposite sides of area $\pi\left(R_{1}^{2}-R_{2}^{2}\right)$. On the outer and inner sides of the metal cylinder there is a ring electrode, and all these parts constitute a capacitor.

With the use of the electrodes there were made applications to the DC voltage $U$ cylindrical capacitor cover that led to the interaction of electric and magnetic fields and the appearance of both the radial and axial components of the electric field. This, together with the geometrical factor - annular shape magnet - LED to the total concentration of the electric field in the capacitor region of space which is at a distance from the center of the device and is located at its center line. The density of the electric field at this point is several orders of magnitude greater than the density of the electric field that arises between the annular covers.

An ohmic contact was created on the back-side annealing of an In-Ni alloy in a vacuum (or under a hydrogen atmosphere) at a temperature of about $600^{\circ} \mathrm{C}$. To avoid undesired contamination, the plates were annealed on a flat surface. This was accompanied by the annealing process of the gold barrier layer, contributing to the decrease of the surface conduction channels formed by the surface states and an improvement of the sensitivity of the final structure.

As is known, the physical nature consists of four basic types of surface states $[9,10]$ which are somehow related to the presence of additional charge that is present on the semiconductor surface or on the full screen in the vicinity of the surface. A feature of the epitaxial structure is that it is generated in a natural growth area of the semiconductor film. Therefore, the surface states of Tamm and Shockley provided therein little probability that this surface is not broken prior to the application of the barrier layer. Two other types of surface states are associated with practical and processing quality of epitaxial layer surface prior to the application of the barrier layer. Thus, in this case, the annealing process takes place in order to reduce the density of the available surface states.

The isolation of photosensitive elements and contact layers is performed by standard techniques of photolithography. Connection conductors are carried by soldered tinned copper conductors to the contact layers. When using the ultrasonic welding, there is used a variant structure where the contact metallization layer of the barrier layer is made out of gold.

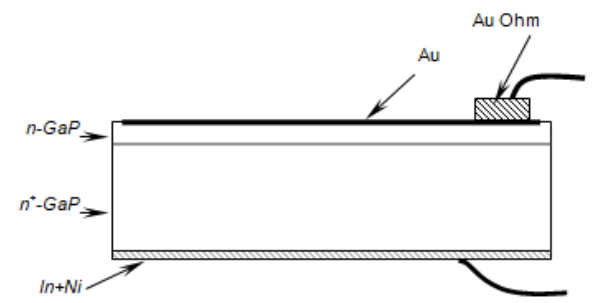

Fig. 1. Construction of the photosensitive member on the basis of the photodiode $n^{+} n$ GaP-Au

Photodiode crystal construction is shown in Figure 1. Shown here is an $\mathrm{n}^{+}$conductivity type of gallium phosphide substrate $\left(\mathrm{n}^{+}-\mathrm{GaP}\right)$. An epitaxial $(\mathrm{n}-\mathrm{GaP})$ layer of $\mathrm{n}$-type conductivity is formed on it. A Schottky barrier is formed on the surface of the epitaxial layer. The material of the barrier layer is gold ( $\mathrm{Au}$ ). Its thickness is $20 \mathrm{~nm}$. On the barrier layer of gold, there is also formed a gold ohmic contact (AuOhm). An ohmic contact of indium with a nickel layer $(\mathrm{In}+\mathrm{Ni})$ is formed on the reverse side of an $n+$ type of gallium phosphide substrate. 


\section{A study of the photodiode}

Fig. 2 shows the difference values of ionized donors and acceptors ND concentration in the surface layer of gallium phosphide before and after the annealing process, calculated according to the measuring capacity of the photosensitive member (PSM) before and after the annealing process.

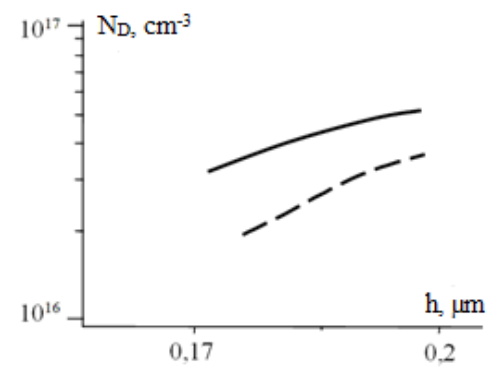

Fig. 2. $N_{D}$ concentration distribution profile in the surface region of the epitaxial layer of gallium phosphide (dashed line - after annealing, solid-before annealing)

Calculation was performed according to [11], in accordance with the formula:

$$
N_{D}=\frac{2}{q \varepsilon_{s}} \frac{(-d U)}{d\left(\frac{1}{C^{2}}\right)},
$$

where $\varepsilon_{\mathrm{s}}=\varepsilon_{0} \varepsilon, \varepsilon_{o}=8.85 \cdot 10^{-12} \mathrm{~F} / \mathrm{m}-$ the dielectric constant, $\varepsilon=10$ - dielectric constant of gallium phosphide, $d U$ - change in the bias voltage, $q$ - the electron charge, $C$ - specific capacity of the photodiode.

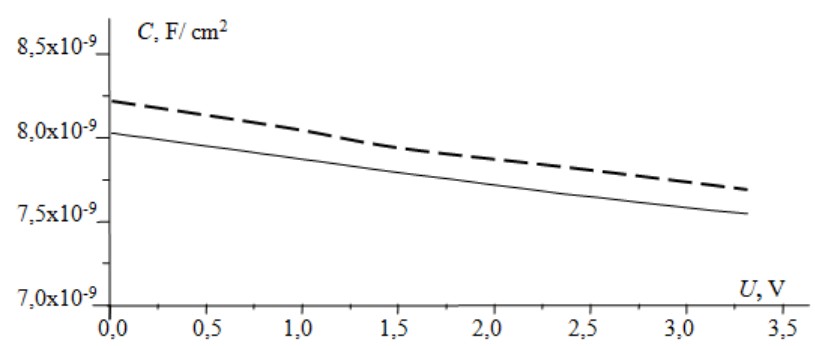

Fig. 3. The capacitance-voltage characteristic of the PSMs (as can be seen, the dependence hardly changes in the operating voltages)

An investigation of the spectral characteristics of the selected photodetectors is conducted with the help of the spectral complex type KSVU-23 by comparing the working standard (photodiode PD $288 \mathrm{~V}$, certified sensitivity to $440 \mathrm{~nm}$ wavelength). The radiation source is used in the respective ranges: in the spectral range from 200 to $400 \mathrm{~nm}$, it was a deuterium lamp with DSA-30; in the spectral range from 400 to $1200 \mathrm{~nm}$ - an incandescent lamp KGM24-150. Used was also a preamplifier precision converter "current-voltage" PPTN-03.

The measured current values of a monochromatic sensitivity and the absolute values are shown in Figure 4.

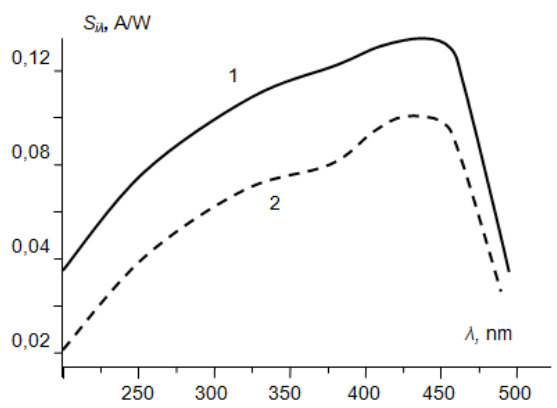

Fig. 4. The absolute spectral sensitivity characteristics of the photodiode of gallium phosphide $(1$-spectral response of the photodiode with the annealed layer of gold, 2 - spectral characteristic photodiode without the annealing)
We can see that at the maximum of the spectral sensitivity characteristics of the photodiode, which was subjected to annealing process, the gold layer has better sensitivity over the entire spectral range.

In particular, at the maximum of spectral characteristics of the proposed photodiode, it has a sensitivity of $0.13 \mathrm{~A} / \mathrm{W}$, and at a wavelength of $254 \mathrm{~nm}$ (wavelength emitted by a germicidal lamp) - about $0.06 \mathrm{~A} / \mathrm{W}$

Measurements of the dark current (IT) are conducted via a precision transducer "current-voltage" PPTN-03 at an operating voltage for the photodiode (UP) $10 \mathrm{mV}$. The voltage $\mathrm{U}$ is measured with a voltmeter. The dark current is calculated by the formula:

$$
I_{T}=\frac{U}{K}
$$

where $K$ - conversion gain PPTN-03 B/A.

According to measurements, the dark current value is not more than $10^{-9} \mathrm{~A}$.

Measurement of sensitivity nonlinearity $\left(\delta_{\mathrm{S}}\right)$ and dynamic range of the photodiodes are conducted in a suitable machine and the method of the luminance increase is calculated with the use of the formula:

$$
\delta_{S}=\frac{\left|\left(U_{1}+U_{2}\right)-U_{3}\right|}{U_{1}+U_{2}}
$$

wherein $U_{1}$ and $U_{2}$ - video output of the photodiode when alternately illuminated with PSM, $U_{3}$ - video output while the photodiode is illuminated by both light fluxes PSM channel settings.

Nonlinearity of the energy generated in the photodiode characteristics oscillates in the range from $10^{-4}$ to $10^{3} \mathrm{~W} / \mathrm{m}^{2}$, according to the formula for measurement and calculation of (4) that does not exceed $1 \%$. Thus, the dynamic range of the photodiode is not less than $10^{7}$.

Conducted was a comparison of a photodiode based on a gallium phosphide, manufactured by a new technology (new UVD), with previously known photodiodes - analogues. Comparison was made with the following photodiodes:

- UV1 based on GaP-Au

- G1962 based on GaP-Au

Table 1 shows the technical specifications of the above photodiodes.

Table 1. Technical characteristics of ultraviolet photodiodes - analogues of the proposed photodiode

\begin{tabular}{|c|c|c|c|}
\hline Name of the parameter & New UVD & G1962 & UV1 \\
\hline $\begin{array}{c}\text { The spectral region } \\
\text { sensitivity, nm }\end{array}$ & $\begin{array}{c}200-480 \\
\left(\lambda_{\max }=440\right)\end{array}$ & $\begin{array}{c}200-480 \\
\left(\lambda_{\max }=440\right)\end{array}$ & $\begin{array}{c}200-450 \\
\left(\lambda_{\max }=370\right)\end{array}$ \\
\hline $\begin{array}{c}\text { Dark current, no more } \\
(\mathrm{Ur}=10 \mathrm{mV}), \mathrm{A}\end{array}$ & $1 \cdot 10^{-9}$ & $5 \cdot 10^{-12}$ & $1 \cdot 10^{-10}$ \\
\hline $\begin{array}{c}\text { Monochromatic sensitivity } \\
(\lambda=400 \text { nm), not less than A/W }\end{array}$ & 0.13 & 0.12 & 0.11 \\
\hline $\begin{array}{c}\text { Dynamic range, times } \\
(\text { with nonlinearity of energy } \\
\text { characteristic } \delta \mathrm{E}= \pm 1 \%)\end{array}$ & $1 \cdot 10^{7}$ & $1 \cdot 10^{7}$ & $1 \cdot 10^{7}$ \\
\hline Area of PSM, mm ${ }^{2}$ & 49 & 5.2 & 10.0 \\
\hline
\end{tabular}


The analysis given in Table 1 shows the following:

1) The proposed photodiode (new UVD) has the same spectral sensitivity range as that of analogues.

2) The level of dark current of the new UVD corresponds to the level of analogues, taking into account the area of the photosensitive element.

3) In terms of sensitivity, the new UVD is superior to analogues having a Schottky barrier contact made of gold.

4) The dynamic range of the new UVD corresponds to its analogues.

Thus, it can be seen that the new UVD, in terms of its technical characteristics, is not inferior to the analogues with the Schottky barrier, but it exceeds them in the area of sensitivity.

\section{Findings}

Presented is a technology-based structure of gallium phosphide $\mathrm{n}^{+}-\mathrm{n}-\mathrm{GaP}-\mathrm{Au}$ photodiode with high sensitivity, which is constructed in particular with ionic gallium phosphide. Ion etching surface before the application of the gold barrier layer is formed on the $\mathrm{GaP}$ substrate in a magnetic field, and is subjected to the annealing process at $600^{\circ} \mathrm{C}$ to form contact with the reverse side of the substrate of indium. The thickness of the barrier of the burning gold is $20 \mathrm{~nm}$.

The maximum spectral sensitivity characteristics obtained by the photodiode is a sensitivity of $0.13 \mathrm{~A} / \mathrm{W}$, and at a wavelength of $254 \mathrm{~nm}$ - about $0.06 \mathrm{~A} / \mathrm{W}$. The dynamic range of the photodiode is not less than $10^{7}$.

\section{D.Sc. Yuri Dobrovolsky}

e-mail: y.dobrovolsky@chnu.edu.ua

Associate Professor at the Department of Physics of Semiconductors and Nanostructures (DPSN). Author of 150 scientific articles and 50 patents The author of 23 developments of measuring equipment.

http://orcid.org/0000-0002-1248-3615

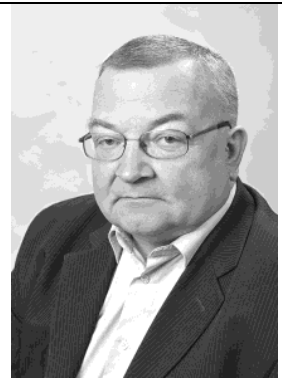

\section{Volodymyr Lipka}

e-mail: olodymyrlipka9@gmail.com

PJC "CDB "Rhythm". Chairman of the Board

The author of 2 scientific articles.

http://orcid.org/0000-0002-5899-6213

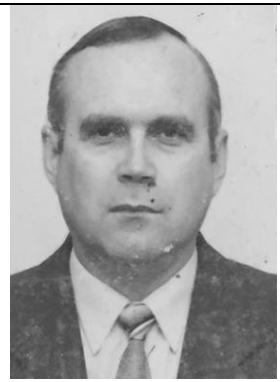

\section{Ph.D. Vladimir Strebezhev}

e-mail: v.strebezhev@chnu.edu.ua

Assistant at DPSN. Author of 10 scientific articles and 2 patents.

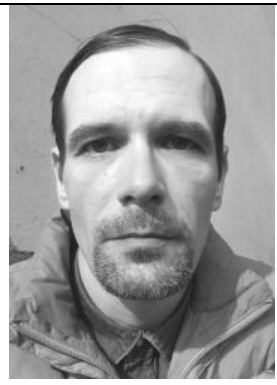

\section{References}

[1] Anisimov I. D., Stafeev V. I.: Ultraviolet photodetectors based on wideband compounds. Applied physics 2/1999, 41-44.

[2] Bix M. P., Dobrovolsky Y. G., Shabashkevich B.: UV Photodetectors based on gallium phosphide. Applied physics 4/2005, 97-100.

[3] Dobrovolsky Y. G.: Photodiode, resistant to ambient lighting. Sensor Electronics and Microsystem Technologies 4/2006, 33-37.

[4] Dobrovolsky Y. G., Pidkamin L., Prokhorov G.: Photodiodes on the basis of gallium phosphate with increased sensitivity at a wavelength of $254 \mathrm{~nm}$. Proceedings SPIE 8338/2011, 83380N [http://doi.org/10.1117/12.920931].

[5] Dobrovolsky Y. G.: Based on GaP photodiode with high sensitivity in the shortwave UV region of the spectrum. TKEA 5/2012, 31-34.

[6] Lamkin I. A., Menkovich E. A., Tarasov S. A.: Ultraviolet photodiodes based metal contacts - solid solutions of gallium nitride and aluminum. Scientific and technical statements STU. Physics and mathematics 3/2012, 28-31.

[7] Malik A. I.: Optoelectronic properties of heteroijunctions metal oxide-gallium phosphide. Semiconductor Physics and Technology 25(10)/1991, 1891-1695.

[8] Malik A. I., Seco A., Fortunator E., Martins R., Shabashkevich B., Piroszenko S.: A new high ultraviolet sensivity FTO-GaP Schottky photodiode fabricated by spray pyrolysis. Semicond. Sci. Technol. 13/1998, 102-107.

[9] Nicollian E. H., Brews J. R.: MOS (Metal Oxide Semiconductor) Physics and Technology. Wiley, New York 1982.

[10] Sah C. T.: Fundamentals of solid-state electronics. World Scientific, 1991.

[11] Sze S. M., Ng K. K.: Physics of Semiconductor Devices. 3rd Edition. John Wiley \& Sons Inc., New Jersey 2006.

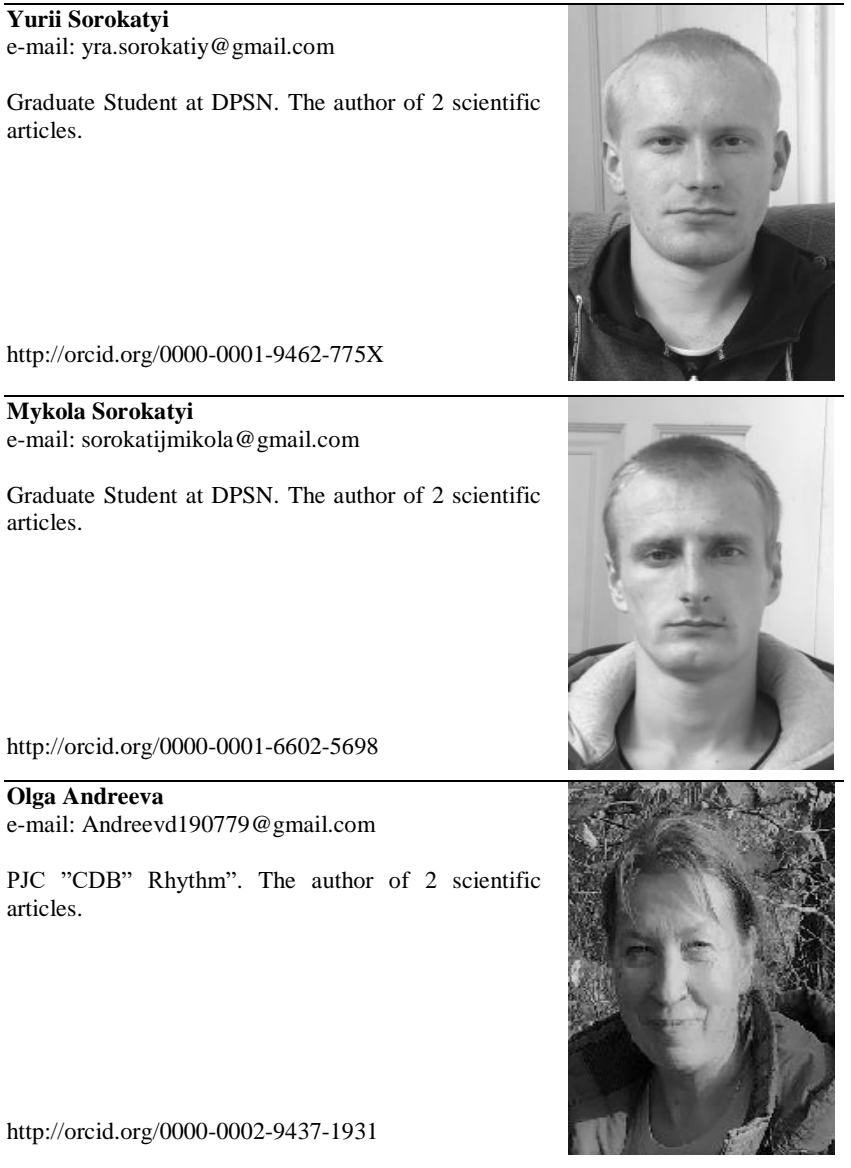

otrzymano/received: 15.11 .2019

przyjęto do druku/accepted: 15.02 .2020 